\title{
Cuidado de Saúde: uma aproximação teórico-filosófica com a fenomenologia
}

\section{Health Care: an approach to theoretical-philosophical phenomenology}

\section{Atención de la Salud: una aproximación a la fenomenología teórico-filosófica}

${ }^{1}$ Telma Elisa Carraro; ${ }^{2}$ Silvana Silveira Kempfer; ${ }^{3}$ Luciara Fabiane Sebold; ${ }^{4}$ Marília de Fátima de Vieira de Oliveira; ${ }^{5}$ Maria Terezinha Zeferino; ${ }^{6}$ Daysi Jung da Silva Ramos; ${ }^{7}$ Ariane Thaise Frello

${ }^{1}$ Enfermeira, Pós Doutora pela Universidade Estadual de São Paulo - USP - Ribeirão Preto, Doutora e Mestra pela Universidade Federal de Santa Catarina.

${ }^{2}$ Enfermeira, Mestre em Enfermagem.

${ }^{3}$ Enfermeira. Doutoranda do Programa de Pós-Graduação em Enfermagem da Universidade Federal de Santa Catarina. ${ }^{4}$ Enfermeira. Doutora do Programa de Pós-Graduação em Enfermagem da Universidade Federal de Santa Catarina. Professora Assistente da Faculdade de Enfermagem da Universidade Federal do Pará.

${ }^{5}$ Enfermeira Doutoranda. Docente do Curso de Enfermagem da Universidade do Sul de Santa Catarina. ${ }^{6}$ Fisioterapeuta. Mestranda pelo Programa de Pós- Graduação em Enfermagem pela Universidade Federal de Santa Catarina.

${ }^{7}$ Enfermeira. Doutoranda do Programa de Pós-Graduação em Enfermagem da Universidade Federal de Santa Catarina.

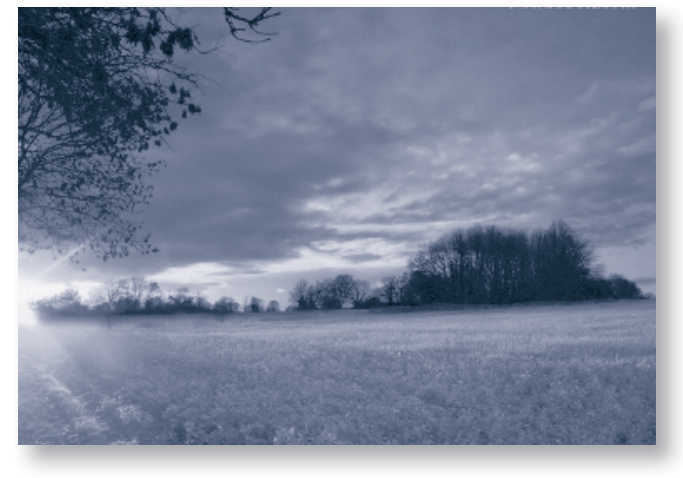

Health Care: an approach to theoreticalphilosophical phenomenology

\section{ABSTRACT}

Think about the care becomes a philosophical reflection, contemplation of a movement of care initiatives that fortify the knowledge that constitute the knowledge in the disciplines of health. This experience report makes approximations of phenomenological philosophy with the ontology of care, which participates in the corpus of knowledge of the disciplines of health. Sought to know through the slit of the time the thought of Socrates, Plato, Aristotle, St. Augustine, Thomas Aquinas, Jean Jacques Rousseau, Immanuel Kant, Hegel, Edmund Husserl, Martin Heidegger, Alfred Schutz, and how these thinkers reflect ontological construction of care to our days. It is observed that the current phenomenological presents, through contributions of these important thinkers in the formation of what is understood today as care and how health professionals are bound by this theoretical basis

Keywords: health care, philosophy, phenomenology.

\section{Atención de la Salud: una aproximación a la fenomenología teórico-filosófica}

\section{RESUMEN}

Pensar sobre el cuidado se convierte en una reflexión filosófica, la contemplación de un movimiento de acciones de cuidado que 
fortalezcan los conocimientos que constituyen el conocimiento en las disciplinas de la salud. Este relato de experiencia favorece las aproximaciones de la filosofía fenomenológica con la ontología de la atención, participando en el corpus de conocimiento de las disciplinas de la salud. Se busca conocer a través del tiempo el pensamiento de Sócrates, Platón, Aristóteles, San Agustín, Santo Tomás de Aquino, Jean Jacques Rousseau, Immanuel Kant, Hegel, Husserl, Edmund, Martin Heidegger, Alfred Schutz, y cómo estos pensadores reflejan construcción ontológica de la atención a nuestros días. Se observa el pensamiento fenomenológico, a través de las contribuciones de estos pensadores en la formación de los profesionales de la salud.

Palabras clave: cuidado de la salud, la filosofía, la fenomenología.

\section{RESUMO}

Pensar sobre o cuidado passa a ser uma reflexão filosófica, um movimento de contemplação das ações de cuidado que fortificam os saberes que constituem o conhecimento nas disciplinas da área da saúde. Este relato de experiência faz aproximações de filósofos fenomenólogos com a ontologia do cuidado, que participa do corpus de conhecimento das disciplinas da área da saúde. Procurou-se conhecer por meio da régua do tempo o pensamento de Sócrates, Platão, Aristóteles, Santo Agostinho, São Tomás de Aquino, Jean Jacques Rousseau, Immanuel Kant, Hegel, Edmund Husserl, Martin Heidegger, Alfred Schutz, e como estes pensadores refletem a construção ontológica do cuidado até nossos dias. Observa-se que a corrente fenomenológica traz por meio destes pensadores importantes contribuições na constituição do que é compreendido hoje como cuidado e de como os profissionais da área da saúde mantêm-se vinculados com este eixo teórico.

Descritores: cuidados de saúde, filosofia, fenomenologia.

\section{INTRODUÇÃO}

A filosofia permeia nossas vidas ao longo do tempo, mesmo que não percebamos claramente, constantemente adotamos atitude filosófica ao contemplar a vida cotidiana e a nós mesmos, passamos assim, a indagar nossas crenças, sentimentos e a nossa existência.

Diante do exposto, é oportuno fazermos alguns questionamentos: O que é filosofia? Para que filosofia? Por que estudar filosofia na saúde? O simples fato de não aceitar de forma passiva as idéias, os fatos, as situações, os valores, os comportamentos de nossa existência cotidiana como óbvias e evidentes sem antes havê-los investigado e compreendido nos remete à um comportamento filosófico. Assim, a filosofia teria como finalidade ensinar-nos a virtude, que é o princípio do bem-viver (Chauí, 2000). Estabelecendo o elo com a saúde, a filosofia passa a incidir por meio da possibilidade de indagar as diversas situações de cuidado nos diferentes cenários e momentos históricos.

As atitudes filosóficas apresentam-se como indagações sobre o mundo que nos rodeia e relações que mantemos com ele. Nesta direção a saúde busca aperfeiçoar seu corpo de conhecimentos no sentido de aprofundar os estudos teórico-filosóficos do cuidado. Esta é a própria reflexão filosófica significando um movimento pelo qual o pensamento volta-se para ele mesmo, interrogando-se, e esta contemplação das ações de cuidado fortificam os saberes.

A “filosofia é uma busca da sabedoria por 
si mesma, que resulta em uma explicação do mundo"(Ferrater-Mora,2005, p.1045). O seu sentido está pautado na investigação dos primeiros princípios, tendo, portanto um papel de fundamento da ciência e de justificação da ação humana. Sendo assim, apresenta um papel questionador, com um sentido de investigação critica, fazendo uma relação reflexiva entre ela e outros campos do saber (Madjarof,2010). Assim, a filosofia se ocupa dos processos que levam as concepções de todos os seres e coisas e os seus respectivos papéis no mundo.

Estas reflexões conduziram a busca pelo percurso filosófico da fenomenologia e o cuidado a partir de Sócrates, destacando neste estudo, alguns pensadores que de alguma forma influenciaram e foram influenciados pelo período histórico em que viveram.

Este relato de experiência teve como objetivo refletir sobre parte da trajetória de alguns filósofos a fim de chegar ao referencial filosófico da fenomenologia. As discussões foram realizadas em uma disciplina da Pós-Graduação em Enfermagem da Universidade Federal de Santa Catarina, intitulada "Estudos fenomenológicos". A disciplina, desenvolvida por meio de metodologias ativas*, ocorreu no segundo semestre de dois mil e nove e teve como objetivos: buscar conhecimentos sobre a fenomenologia; relacionar a fenomenologia com o cuidado e conforto; pautar os estudos fenomenológicos voltados para a construção dos referenciais teórico-filosóficos de teses e dissertações dos pós-graduandos participantes da disciplina.

O grupo de estudos constituiu-se de seis alunas e a professora da disciplina. Destas, seis são enfermeiras e uma é fisioterapeuta. Os encontros eram organizados coletivamente, numa periodicidade quinzenal onde aconteciam leituras e reflexões sobre a contribuição filosófica de alguns pensadores de expressão na história do conhecimento humano. $\mathrm{O}$ intuito do grupo era o de estruturar uma régua do tempo para uma aproximação com a temática que envolve a fenomenologia enquanto movimento filosófico. Dessa forma, visualizamos abaixo:

Figura 1 - Régua do Tempo dos Filósofos 
estas atitudes filosóficas do cuidado quando preservamos tais virtudes humanas junto às pessoas nas mais variadas situações relacionadas à saúde.

Essas virtudes e o pensamento buscam pela verdade e esta, relacionada com o bem, tem como seu principal discípulo Platão (Grécia, 427-347 a.C.), que transcreveu os discursos de seu mestre, Sócrates. Este pensador fundou a Academia explorando os temas a respeito da ética, política, metafísica e a teoria do conhecimento ou conhecimento certo. A ética, neste contexto, significa o que é bom para o indivíduo e para a sociedade; política para o povo grego refere-se aos cidadãos, pertence aos cidadãos; metafísica é um dos ramos da filosofia, estuda a essência do mundo tendo seu foco central na ontologia; que é o estudo da natureza do ser, da realidade, da existência dos entes, trata do ser enquanto ser; a teoria do conhecimento ou conhecimento certo era descrito como ciência, devendo corresponder à realidade, sendo em alguns momentos dotadas de conceitos universais, necessários, imutáveis e eternos. Neste, o existir é fenomenal, um outro mundo de realidades, objetivamente dotadas dos mesmos atributos dos conceitos subjetivos que as representam (Rogue,2007).

A partir dos ensinamentos de Sócrates e Platão, seu sucessor Aristóteles (Grécia, 384332 a.C.), passou a observar e refletir acerca da natureza e tudo o que a envolve de forma mais sistemática, através da lógica, uma perspectiva criada para explicar as experiências humanas, a qual utiliza-se de um método centrado em premissas que geram uma conclusão a partir delas. Por isto, seus escritos denominados como organón, fazem referência à lógica formal e à teoria do juízo. Pode-se vincular o pensamento aristotélico a uma aproximação com o sensível, voltado as experiências humanas e a fenomenologia (Aristoteles, 2007).

Desta forma, compreendemos que são essas experiências humanas que constituem o cotidiano das relações de cuidado no contexto da saúde e da doença. Pois, os encaminhamentos que estes pensadores já faziam numa maneira especial de se relacionar com o mundo está significativamente presente quando nos incomodamos ou estranhamos determinadas situações no cotidiano do processo de cuidar. Portanto, o fato de existir a inconformidade já traduz a presença de várias questões do pensamento filosófico fenomenológico.

Santo Agostinho (África do Norte, 354430), estudou sobre os escritos de Platão. Elaborou uma aproximação entre a teologia e a filosofia, o cristianismo e a filosofia de Platão, sendo assim a primeira grande síntese entre o pensamento cristão e a filosofia grega, o chamado platonismo cristão. Foi o primeiro pensador a desenvolver uma noção de interioridade - é olhando para o seu interior que o homem descobre a verdade; o que prenuncia o conceito de subjetividade do pensamento moderno. Seus estudos foram fundamentais para a consolidação da Igreja na Idade Média e sua influência como teólogo e filósofo foi tamanha que se estendeu até o século XVII, conhecido como o século de Agostinho (Marcondes, 2008).

São Tomás de Aquino (Itália, 1225-1274), desenvolveu uma filosofia própria, de forma sistemática, abordou as questões filosóficas e teológicas da sua época, baseou-se em Aristóteles. Seus escritos tiveram como objetivo central organizar um conjunto de argumentos para demonstrar e defender as revelações do cristianismo, de modo a não contrariar a fé. Mostrou que há compatibilidade entre o pensamento cristão e o aristotélico, impactando os movimentos da igreja católica por vários sécu- 


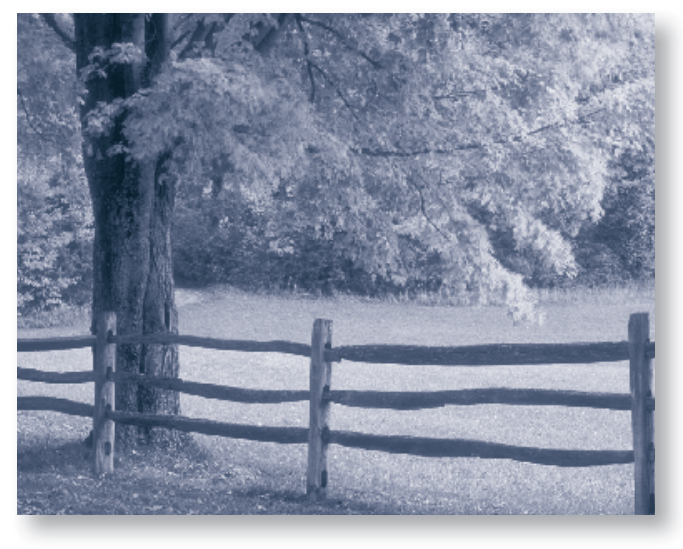

los (Marcondes, 2008).

Pensar o cuidado em saúde sob o aspecto filosófico teológico no mundo contemporâneo, nos mostra uma possiblidade humana de disposição para o outro. E nesse modo de ser próprio de pensar as questões da saúde nos remete a própria existencialidade expressa por pensadores como Jean-Jacques Rousseau (Suiça,1712-1778), que com suas idéias buscou meios para diminuir as injustiças resultantes da desigualdade social, criticando a propriedade privada como causa da miséria entre as pessoas. Acreditava que o ser humano poderia encontrar Deus em seu próprio coração. Entendia o homem natural como um ser solitário, com instinto de autopreservação, compaixão e razão potencial, sem a preocupação em manter as relações sociais (Oliveira,2009).

Rousseau afirmava que é preciso abandonar alguns instintos naturais e aprender a limitar a própria liberdade em função do outro; que os indivíduos precisam preocupar-se com as consequências de seus atos, reconhecendo a necessidade de convivência com outros indivíduos. Valorizava ainda a educação. Entendia que os pais são os primeiros educadores e a verdadeira finalidade da educação é ensinar a criança a viver e aprender a exercer a liberdade (Neto, 2009; Souza,2 009).

Percebemos que o cuidado está presente na vida e obra de Rousseau iniciando através de sua preocupação com a natureza e com o homem e que a educação pode auxiliar o ser humano a ser melhor, esteja ele isolado ou em sociedade. Esse é o modo de ser do cuidado que almejamos em saúde, onde o sentido fenomenológico da preocupação com o outro traduz a essência da preservação da vida.

Como um racionalista, Immanuel Kant (Alemanha, 1724-1804), elaborou o idealismo transcendental, onde todos trazem formas e conceitos a priori (aqueles que não vêm da experiência) para a experiência concreta do mundo, os quais seriam de outra forma impossível de determinar. A sua obra "Crítica da Razão Pura" o autor teve a intenção de pronunciar-se ao valor dos conhecimentos puramente racionais, como deve ser a metafísica, ou seja é necessário a busca na própria razão das regras e os limites de sua atividade, com o intuito de saber até que ponto devemos confiar na razão (Pascal, 2007).

Simultaneamente, emergiu o pensamento de Georg Hegel (Alemanha, 1770-1831), entendido como filosofia da totalidade, criando uma forma de ver e interpretar o mundo baseado na dialética, a qual configura-se em um movimento contínuo de: afirmação, chamado de tese; de negação, chamado de antítese; permitindo elaborar a síntese, que vincula-se a um novo olhar, uma nova percepção da realidade, e que por consequência, geram um novo ciclo dialético (Hegel, 2007). A forma dialética de constituir o conhecimento a partir de uma afirmação, negação e síntese, aponta possibilidades para que o cuidado seja sistematizado, organizado e implementado.

Neste cenário filosófico o pensamento existencial foi discutido a partir de Edmund Husserl (Alemanha,1859-1938), fundador da fenomenologia, considerada como um método de 
descrição e análise da consciência através do qual a filosofia tenta alcançar uma condição estritamente científica. Em outras palavras, fenomenologia é o estudo dos fenômenos, ou seja, um método de descrição da experiência do sujeito (Depraz, 2007). Seu princípio metodológico fundamental, a redução fenomenológica, preocupava-se com a experiência básica da consciência, não interpretada, e a questão do que é a essência das coisas, a reducão eidética (Cobra, 2010). Definiu como redução transcendental a redução da coisa aos detalhes da sua apreensão como fenômeno da consciência propriamente; significava retirá-la de uma visão teórica, transcendente, para tomar conhecimento dela de modo preciso e objetivo, analítico, como simples experiência de consciência (Cobra, 2010).

A fenomenologia apresentada por Husserl permite observar, interpretar e compreender os fenômenos, sendo estes, constituídos pelas vivências e experiências humanas, em especial retratando neste contexto, o cuidado. Volta-se agora o olhar para as coisas mesmas, para a essência do sujeito e suas conexões com a realidade ou o mundo-da-vida, que fazem parte do contexto das disciplinas da área da saúde que trabalham diretamente com o ser humano em seu momento de maior fragilidade, e nesse sentido é necessário conhecer o outro para cuidar.

O mais conhecido discípulo de Husserl foi Martin Heidegger (Alemanha, 1889-1976), que trouxe a possibilidade de um cuidado mais autêntico ressaltando que o processo de cuidar e confortar na prática de saúde, em sua natureza, está envolvido por modos de ser e fazer que não se ocupam somente do que é feito manualmente ou por meio de aparatos tecnológicos para que se concretizem de forma segura. Mas ao contrário, cuidado e o conforto são condutas diante da vida humana que além de habilidades técnicas requerem fundamentação teórica, pensamento crítico e responsável que reconheça as diferenças e limitações existentes no cotidiano.

Neste tempo de cuidado contemporâneo, as atitudes de comprometimento com o outro se diluem facilmente em meio aos modos excêntricos da ciência e da tecnologia, e isso parece nos deixar acostumados, achando que vivemos da melhor maneira possível, e que assegurar a vida a qualquer custo passa a ser imperativo. No entanto, se pensarmos em um tempo cronológico, no início do século $\mathrm{XX}$ Heidegger já estabelecia uma diferença entre os modos do humano frente à tecnologia vigente. Ele escrevia seus artigos contra o modernismo com incursões que hoje nos fazem refletir em torno do cuidado que nos identifica enquanto profissionais de saúde.

No resgate ao Dasein (ser-aí) heideggeriano entendemos que carecemos de um contexto de cuidado autêntico capaz de considerar a técnica não somente por ela mesma, mas sempre com a reflexão crítica de que o humano, enquanto àquele que realiza o cuidado, possui limites, é um ser temporal que tem espaço marcado. A manifestação dos modos de cuidar de alguém deve estar pautada em atitudes comprometidas, pois o cuidado de um tempo moderno, reconhecido pelo domínio tecnicista precisa também ser pensado, e não somente realizado por meio de aplicativos e/ou evidências objetivas, pois considera-se também a experiência e o conhecimento individual. Nesse mesmo entendimento, "ao assumir o cuidado, durante as 24 horas do dia, a Saúde necessita tomar posição também quanto à sua responsabilidade ética, legal e moral, e não apenas técnica e científica" (Carraro et al, 2008, p.504).

Assim, o sentido de cuidado em Heide- 
gger, nos mostra que o cuidado do ser-aí é uma dinâmica que reúne a si próprio diante da compreensão de certa incompletude, e da iminente necessidade de lançar-se à sua realização em cada instante da existência, ou seja, é movimento contínuo, é reflexão, é pensar criticamente diante das inúmeras situações e possibilidades de cuidado. Esse é o contexto da identidade própria do humano que é construída na co-existência e na inter-relação (Silva et al, 2009).

Por fim, em correspondência com os escritos da filosofia heideggeriana compreendemos que para se chegar a um cuidado autêntico, capaz de nos aproximar da essência do cuidado devemos passar pelo que é correto, aquilo que exprime verdade, pelo que dá dignidade e respeita o limite humano. Precisamos estar em constante processo de interrogação: $\mathrm{O}$ que nos unifica enquanto saúde no contexto do cuidado? O que é a essência do cuidado? Qual o meu limite enquanto humano diante da vida humana? Pois, enquanto não assumirmos uma postura reflexiva continuaremos presos na condição inautêntica de ser, sem possibilidade de ultrapassar o comum e violando a dignidade humana. Neste sentido entendemos que "somente onde um tal desocultamento acontece dá-se o que é verdadeiro"(Heidegger, 2007, p. 377).

Entretanto, a fenomenologia assume outro olhar, onde o humano passa a ser considerado não somente como um uno, mas como um ser social, trazido pelo pensamento de Alfred Schutz (Áustria, 1899-1959), que tinha o propósito de estabelecer os fundamentos de uma sociologia fenomenológica compreensiva embasada nas idéias de Max Weber e Edmund Husserl. Os pensamentos de Schutz foram sendo estabelecidos no sentido de fundamentar filosoficamente as ciências sociais, procurando saber o que é a sociologia nela mesma. Para isto, Schutz se apropria dos conceitos Husserlianos de intencionalidade, intersubjetividade e Lebenswelt (mundo vivido), além, dos conceitos Weberianos de ação, ação social e compreensão, tendo, então, a tarefa de esclarecer o sentido objetivo e o sentido subjetivo da ação. Entendeu que a resolução deste problema requer uma reflexão filosófica para a elaboração de uma teoria da ação humana e de sua compreensão, e buscou na fenomenologia as suas respostas. Dessa forma, Schutz fundamentou a sua teoria e levou a fenomenologia para o mundo da vida onde o homem se encontra situado (Schutz, 1979).

As contribuições do pensamento de Alfred Schutz na ação do cuidado caracterizam-se em ver o outro na sua dimensão humana e social no mundo da vida. Para cuidar precisamos conhecer a vida do outro, a sua situação biográfica, a sua bagagem de conhecimentos. Sendo assim, os estudos pautados em Schutz produzem conhecimentos que podem ser aplicados no mundo da vida da enfermagem em sua ação de cuidado.

A filosofia é um terreno fértil que fundamenta as discussões sobre o cuidado. Tendo em vista que o ato de cuidar preserva a própria vida, são as contemplações dos modos de ser no mundo que promovem a ampliação dos conhecimentos fenômeno Cuidar. Assim é imperativo ver o outro como um ser de direitos, dignidade e singularidade, e proporcionar meios mecanismos para desenvolver a afetividade, a abertura para a escuta e o diálogo, pois estes são valores construídos pelo ser ao longo de sua existência (Fontana, 2010).

\section{CONSIDERAÇÕES FINAIS}

Reconhece-se a existência de outros autores e correntes de pensamento, porém em fun- 
ção do objetivo deste estudo e a ligação com a fenomenologia estes subsidiaram a reflexão.

O pensamento filosófico constitui-se em alicerce para os profissionais da saúde no que se refere ao cuidado, que mantêm um corpus de conhecimento tangenciado por diversas disciplinas e correntes teóricas, dentre elas a fenomenologia, que traz por meio de sua concepção de mundo e de ciência, um arcabouço para fundamentar o cuidado.

Percebe-se que o cuidado sob o olhar fenomenológico assume características axiomáticas, ontológicas, essenciais na saúde, na medida em que proporciona aos profissionais desvelar suas ações cotidianas imanentes ao ser que cuida e o ser que é cuidado.

\section{REFERÊNCIAS}

- Aristóteles.(2007) Ética a Nicômaco. Tradução: Pietro Nassetti. Martin Claret, São Paulo.

- Carraro, TE et al. (2008) O papel da equipe de saúde no cuidado e conforto no trabalho de parto e parto: opinião de puérperas. Texto Contexto Enferm, 17, 502-9.

- Chauí, M. (2000) Convite à filosofia. Ática, São Paulo.

- Cobra, RQ. (2010) Edmund Husserl. filosofia Contemporânea.Disponível em: http://www.cobra.pages.com.br. [Consult. 02 de Nov de 2010].

- Ferrater-Mora, J. (2005) Dicionário de Filosofia. Loyola, São Paulo.

- Fontana, RT. (2010) Humanização no processo de trabalho em enfermagem: uma reflexão. Rev Rene 11,200207.

- Heidegger, M. (2007) A questão da técnica. Scientiae studia 5, 375-98.

- Hegel. (2007) Fé e Saber. Hedra, São Paulo.

- Depraz, N. (2007) Compreender Husserl. Vozes, Petropolis.

- Japiassu, H; Marcondes, D. (2006) Dicionário básico de filosofia. Zahar, Rio de Janeiro.

- Madjarof, R. (2010) Platão. [Internet] Disponível em http://www.mundodosfilosofos.com.br/platao.htm. [Consult. 02 de fev 2010].
- Marcondes D. (2008) Iniciação à história da filosofia: Dos Pré-Socráticos a Wittgenstein. Jorge Zahar, Rio de Janeiro.

- Oliveira, AS. (2009) J-J Rousseau e o discurso sobre a origem e os fundamentos da desigualdade entre os homens. Disponível em:http://www.unicamp.br/ jmarques/cursos/rousseau2001/aso.htm [Consult. 02 de out 2009].

- Neto, MD. (2009) Rousseau: política, educação e liberdade.Disponível em http://www.unicamp.br/ jmarques/ cursos/rousseau2000/mdn.htm. [Consult. 02 de out 2009].

- Pascal, G. (2007) Compreender Kant. Vozes, Petrópolis.

- Rogue, C. (2007) Compreender Platão. Vozes, Rio de Janeiro.

- Souza, AC. (2009) Rousseau: a arte da filosofia, literatura e educação. Disponível em: http://www.unicamp. br/ jmarques/cursos/rousseau2001/acs.htm [Consult. 02 de out 2009].

- Silva, IJ. et al. (2009) Cuidado, autocuidado e cuidado de si: uma compreensão paradigmática para o cuidado de saúde. Rev. Esc. Enfer, 43, 697-703.

- Schutz, A. (1979) Fenomenologia e relações sociais. Zahar, Rio de Janeiro. 